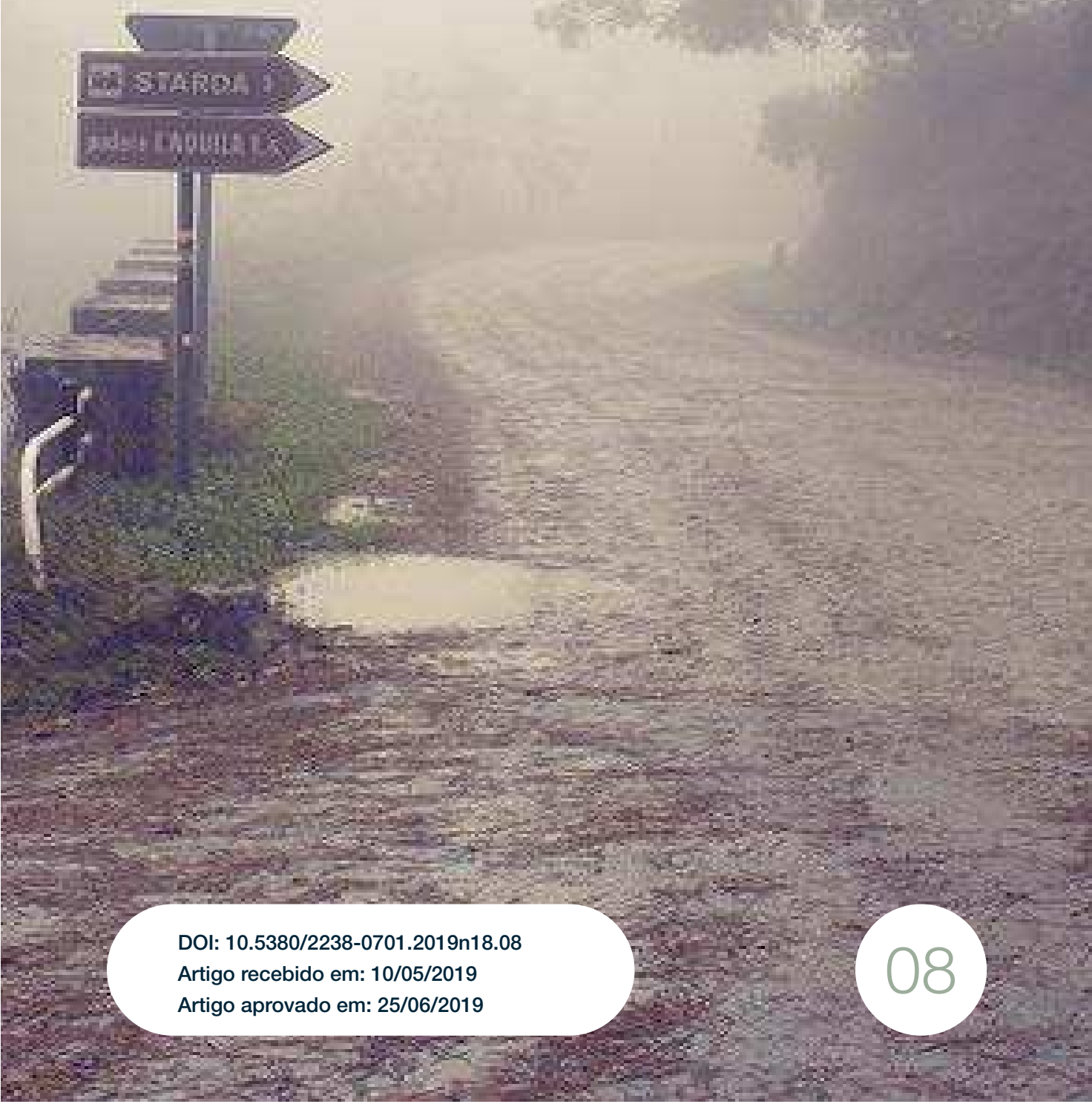


Numa encruzilhada, dois campos: a lágrima como meio nas experiências do sagrado e de luta política contracolonial do Rosário negro e do Ñembo'e Kaiowá 


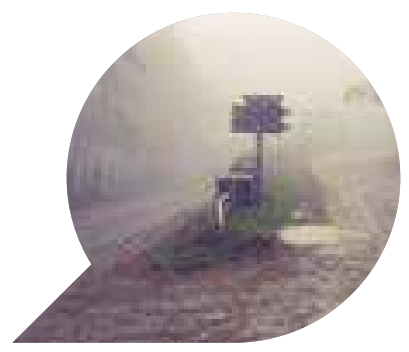

\title{
Numa encruzilhada, dois campos: a lágrima como meio nas experiências do sagrado e de luta política contracolonial do Rosário negro e do Nembo'e Kaiowá
}

\author{
At a crossroads, two fields: the tear like medium \\ at the sacred experiences and counter colonial \\ political struggle of the black Rosário and the \\ Kaiowá Nem-bo'e
}

En una encrucijada, dos campos: la lagrima como medio en las experiencias del sagrado y lucha política contra-colonial en el Rosário negro y en en Nem-bo’e Kaiowá

LUCIANA DE OLIVEIRA ${ }^{1}$

BÁRBARA REGINA ALTIVO ${ }^{2}$

Resumo: Como formas de vida, experienciadas na fronteira com o regime de visibilidade Ocidental-moderno e violentamente exterminadas por ele, realizam mediações comunicacionais afins às suas

1 Professora associada do Departamento de Comunicação Social e do Programa de Pós-Graduação em Co-municação da UFMG. É pesquisadora líder do Coletivo de Eștudos, Pesquisas Etnográficas e Ação Comunicacional em Contextos de Risco (Corisco). E-mail: luciana.Iucyoli@gmail.com

2 Jornalista e antropóloga, doutora em Comunicação Social pelo PPGCOM/UFMG. E-mail; barbaralti-vo@gmail.com 
cosmologias como forma de afirmação política? Uma semente conta de lágrima ou mboy em língua guarani -, usada nos rosários trançados sobre os corpos negros nos Reinados (expressão religiosa de matriz africana) e nos jeasaha sobre os corpos dos rezadores Kaiowá (em experiências xamânicas desse povo indígena), é meio de comunicação com antepassados, entidades sagradas e elementos que nos-sa filosofia chama de naturais. O artigo tem por objetivo presentificar, via experiências etnográficas, processos de comunicação multidimensionais e o sentido de meio em agenciamentos contracoloniais que fazem pensar sobre o tempo, o território e o relacional no campo da Comunicação.

Palavra-chave: Xamanismo Kaiowá; Reinado de Nossa Senhora do Rosário; Meio de Comunicação; Subjetivação Política.

Abstract: How forms of life, experienced on the border with modern-Ocidental visibility regime and extermi-nated by it, perform communicational mediations related to their cosmologies like a form of political affirmation? A seed - tear beads, mboy in guarani language - used in the Rosaries braided over the black bodies at the Reinado (afro-brazilian religiosity expression) as well in the jeasaha over the Kaiowa prayers bodies (in shamanic experiences of this indigenous people in Mato Grosso do Sul State, Brazil) is a medium to communicate with ancestors, sacred entities and elements that our phi-losophy calls natural ones. The article aims to make present, toward ethnographic experiences, a mul-tidimensional communication processes and the sense of medium in counter colonial agencies, mak-ing to think about the relational in the communication processes.

Keywords: Kaiowa Shamanism; Nossa Senhora do Rosário Kingdom; Medium; Political subjectivation.

Resumen: Cómo las formas de vida, experimentadas en la frontera con el régimen de visibilidad moderno-Occidental y violentamente exterminadas por él, realizan mediaciones comunicacionales afines a sus cosmologías como de afirmación política? Una semilla, lágrima de la Virgen del Rosário o mboy en lengua guaraní -, usada en 
los rosarios trenzados sobre los cuerpos negros en los Reinados (expre-sión religiosa de matriz africana) y en los jeasaha sobre los cuerpos de los chamanes Kaiowa (en las experiencias de reza ritual de ese pueblo indígena), ambos en Brasil, es una medio de comunicación con los ancestros, las entidades sagradas y los elementos que nuestra filosofía llama naturales. El artículo tiene por objetivo presentificar, vía experiencias etnográficas, procesos de comunicación multidimensionales y el sentido de médium en agenciamentos contra-coloniales que hacen pensar sobre el relacional en la comunicación.

Palabras-clave: Chamanismo Kaiowa. Reinado de la Virgen del Rosário. Medio de comunicación. Subjetivación política.

\section{Introdução}

Este trabalho configura um experimento textual que elabora conjuntamente duas diferentes e interli-gadas vivências etnográficas guiadas pela postura das pesquisadoras enquanto aprendizes de outras filosofias e formas de vida. Por meio de um diálogo que emerge da intensidade da imersão em cam-po e momentos de pesquisa, o encontro com a realidade do povo indígena Kaiowá, no Mato Grosso do Sul, na retomada Guaiviry e com uma comunidade afro-brasileira de Reinado no centro-oeste de Minas Gerais, consubstancia-se, por um lado, na interface com o campo da antropologia e, por outro lado, a partir de uma semente a lágrima de Nossa Senhora, conta de lágrima, mboy em língua gua-rani, e de dois artefatos, o Rosário e o jeasaha - que, além de um parentesco estético, são, a um só tempo, meios de comunicação e de subjetivação e luta política em ambos os contextos.

A apresentação e articulação de conceitos dos dois campos, marcados por cosmologias de alta complexidade filosófica e espessa imaginação mitopoética, exigem alguns esforços elucidativos à leitura do trabalho. O primeiro deles é compreender que priorizaremos as referências bibliográficas imanentes às sociedades pesquisadas e suas autoridades intelectuais, em diálogo simétrico com espe-cialistas acadêmicos. Todos os termos dos povos estudados serão apresentados em itálico na sua primeira aparição e explicados brevemente em nota de pé de página ou 
no corpo do texto. São qua-tro os momentos formadores do fluxo de sentido que propomos: 1) a apresentação das experiências e informações vinculadas ao aprendizado junto ao povo indígena Kaiowá, tendo como mote a rela-ção da conta mboy com a luta pelos territórios originários (o tekoha); 2) o relato do campo junto à Irmandade de Reinado "Os Leonídios", em Oliveira (MG), a partir dos ensinamentos da liderança política e espiritual da comunidade sobre a matriz africana da festa concretizada no Rosário de con-tas de lágrimas de Nossa Senhora; 3) o estabelecimento de um diálogo interepistêmico que, incitado por uma proposta de fórum cosmopolítico, pontua possíveis interfaces entre meios e subjetivação política; 4) explicitamos alguns aspectos de relevância teórico-conceitual para o campo dos estudos da comunicação, com base nas reflexões tecidas ao longo do artigo, especialmente no que tange no-ção de meio que emerge, em movimento indutivo, do campo ao trato conceitual.

O que buscamos no artigo é afirmar onde e de que modo destacamse resistências contraco-loniais (SANTOS, 2015) que provocam rupturas inventivas com formas de poder sobredeterminado-ras e autoritárias, inscritas em circuitos, por assim dizer, paramidiáticos (OLIVEIRA, 2017). Os agenciamentos propiciados pela conta de lágrimas como meio de comunicação que incide no fortale-cimento das subjetividades são sensivelmente experienciados de forma multidimensional com antepassados indígenas e negros, com forças da natureza e divindades, bem como a partir da potência de relação com a matriz feminina de geração e sustentáculo da vida comum - as grandes mães Ñandesy e Nossa Senhora do Rosário. O que evidencia, como buscaremos demonstrar, a biopotência (PEL-BART, 2007). 


\title{
O Jeasaha, a experiência xamânica e a luta pela terra do povo Kaiowá ${ }^{3}$
}

\author{
Lugar dos relâmpagos sem fim \\ Aqui estou vendo todos com a mesma pintura \\ Estou vindo com o brilho, com o brilho me protegendo \\ (Excerto Reza Longa)
}

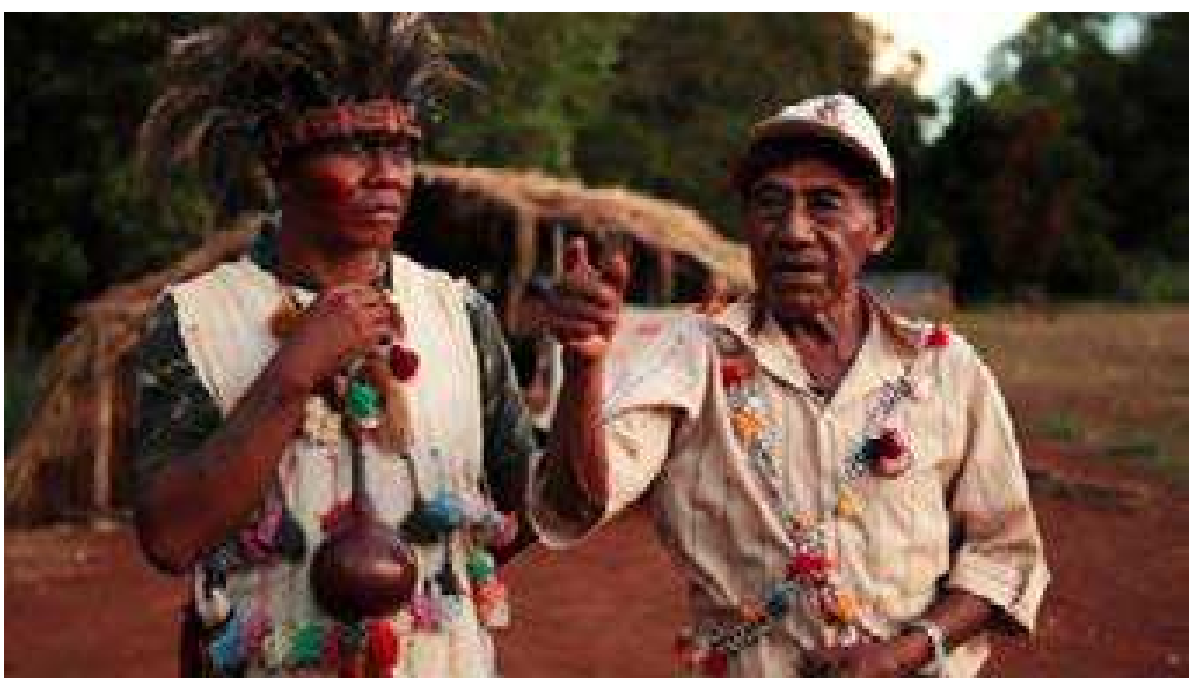

Imagem 1: Rezador Valdomiro Flores (à dir.) portando seu jeasaha em cerimônia político-religiosa no Tekoha Guaiviry/2014. Acervo de Genito Gomes (à esq.) cedido à Luciana de Oliveira

\footnotetext{
3 Relato de Luciana de Oliveira. Minha parceria com o povo Kaiowa tem se desdobrado em ações de pesquisa, extensão e artes visuais, consolidadas em torno do Programa de Extensão Imagem Canto Palavra nos Territórios Gua-rani e Kaiowa (2014-Atual) e da pesquisa "Regimes de Conhecimento e Formas de Vida na Universidade: experiências e experimentos cosmopolíticos em face de conhecimentos tradicionais e outras epistemologias do (in) visível" que con-tou com financiamento do Proext/2014 e conta com financiamento da Prograd/UFMG 2015-atual, Edital Universal da Fapemig (2017-Atual) e do Edital Rumos Itaú-Cultural (2017/2018). Dentre vários produtos e relações, destacam-se o blog do Aty Guasu. (http://atyguasu.blogspot.com), os filmes Ava Yvy Vera (Terra do Povo do Raio, 2016, 52'), Ava Marangatu (O ser sagrado, 2016, 15') e Yvy Pyte (Coração da Terra, 2018, 7’) e o projeto Bordados pela Paz Guarani Kaiowa Brasil (https://www.facebook.com/bordadospelapazguaranikaiowabrasil/?ref=bookmarks). Programa e proje-to têm provocado um fluxo bilateral entre a tekoha Guaiviry-MS e a universidade. Os dois principais intelectuais kaiowa aqui citados, Valdomiro Flores e Daniel Lemes Vasques, foram professores, respectivamente, nos cursos Cos-mociência Guarani e Kaiowa (1/2014) e Ojuhu Ñe'e/Ombopaje Ñe'e (Encontrar a Palavra/Encantar a Palavra - 2/2016)
} 
O trabalho de campo em Mato Grosso do Sul começa em 2012, motivado pelos relatos de as-sassinatos e violação de direitos vivenciados pelos rappers Bruno e Clemerson Verón, do grupo Brô MC's, e pelo aprendiz de xamã Valmir Gonçalves Cabreira. O povo indígena Kaiowá, falante da língua guarani, soma junto com o povo Ñandeva, também conhecido como Guarani, aproximada-mente 50 mil pessoas. A maior parte delas vive em reservas, aldeias artificialmente criadas por políti-cas públicas estatais que retiraram os Kaiowá de seus territórios originários e criaram, ao longo do século XX, uma situação de confinamento territorial (BRAND, 1993;1997). O objetivo da criação desses aldeamentos, sob a égide de um pensamento positivista e capitaneadas pelo órgão indigenista do estado brasileiro, o Serviço de Proteção ao Índio (SPI, que se tornaria a Fundação Nacional do Índio - FUNAl em 1967), era, do ponto de vista ideológico, a assimilação dos indígenas à nascente sociedade moderna brasileira. Do ponto de vista prático, serviram a diversos interesses e ciclos econômicos: extração da erva-mate e madeira, criação extensiva de gado, monocultura e agronegó-cio internacional do milho, da soja e da cana-de-açúcar.

Historicamente, o povo Kaiowá tentou manter os vínculos com seu modo de vida ou teko indo para os fundos das fazendas ou tekoharizando as reservas (PEREIRA, 2014), mas ambos os movi-mentos tornaramse inviáveis no contexto de formação dos latifúndios de monocultura, no período compreendido entre os anos 1950 e1970, com a derrubada final das matas e da vegetação de cerra-do bem como com o aumento populacional nas reservas. Quando isso aconteceu, eles fizeram uma corajosa virada à visibilidade (OLIVEIRA; BENITES; OLIVEIRA NETO; 2016; OLIVEIRA, 2016; OLIVEIRA, 2018), nos termos mesmo dos karai kuera (os brancos): vão aos espaços públicos e às arenas institucionais lutar por seus territórios e afirmar sua existência, organizam um dos maiores movimentos indígenas de toda a América - o Aty Guasu (Grande Assembleia Guarani-Kaiowá) - e, o mais notável, retornam aos seus territórios originários contando com a força de sua reza ancestral, alguns arcos, flechas e bordunas, suprimentos aportados por apoiadores e muita coragem para en-frentar a força bélica oficial e extraoficial de fazendeiros que têm matado impunemente lideranças espirituais e políticas (OLIVEIRA; BOMBA, 2018) e, junto com elas, importantes conhecimentos e formas de reproduzi-los e expandi-los. 
Tal retorno é a expressão máxima do desejo de afirmar uma forma de vida (AGAMBEN, 2000). O tekoha é um fundamento de criação e revivência da experiência Kaiowá. Segundo o reza-dor Valdomiro Flores (2014), os elementos que compõem o teko são: reza (mburahei, ñembo'e), fa-mília extensa (te'yı), roça (kokue), a sociabilidade doméstica nas rodas de chima e tereré, bem como a sociabilidade ampliada dos rituais de dança e festa que ocupam o pátio (oka) entre as casas das lideranças (koty) e a casa grande (ongusu), nos quais se cantam os guahu e cotyhu (cantos de propiciação e festa), celebrados com a chicha ou kagwin (bebida fermentada de milho branco ou amarelo, mandioca e outros). Daniel Lemes Vasques (OLIVEIRA; FLORES; GOMES; VASQUES;2016) destaca o papel da escola indígena como experiência diferenciante na transmissão de conhecimentos que sirvam tanto para potenciar vivências da tradição quanto para criar novas armas para as lidas interculturais, sobretudo aquelas marcadas pelo contato com o mundo dos karaí (brancos). Almeida (2001, p. 19) traduz o que guaraniólogos clássicos como Montoya, Meliá e Susnik entendem desse conceito filosófico-experiencial, em larga medida sobrecodificado pelos modos de entendimento ocidentais acerca do que é a cultura, como "ser, estado de vida, condição, estar costume, lei, hábito" ou ainda "modo de ser, modo de estar, sistema, lei, cultura, norma, comportamento, hábito, condi-ção, costume".

Os anos de convivência e aprendizado intenso com os Kaiowá ensinaram-me que o lugar físico expresso na palavra, no entanto, conectase com o plano cosmológico e, nesse sentido, é im-portante retornar ao que essa imaginação filosófica concebeu acerca da criação da terra por dois mo-tivos: 1) compreender que a luta pela terra é a luta por um território geográfico-cosmológico; 2) compreender a figura sagrada de Ñandesy e a força da semente mboy (conta de lágrima). Vasques (2012; 2016a), historiador kaiowá, aprendiz de xamã e professor do tekoha Guaiviry, contou-me que os primeiros seres viventes, inicialmente sem distinção ou marcas de gênero, nascidos em brumas de reza a partir do jesuka (esperma originário), Ñanderu e Ñandesy, o casal de demiurgos-criadores, cada qual escolhe uma parte do jesuka: Ñanderu, o esperma, e Ñandesy, o óvulo, tornando-se a ima-gem do que concebemos como o homem e a mulher. Deles e desse encontro, ainda embalados na reza-murmúrio dos primeiros cantos ñemboé do casal-criador, decorre uma segunda geração de seres viventes, denominados por meu interlocutor de semideuses, 
que compõem uma miríade de entidades cuja vida é sagrada e dedicada a cuidar das coisas do mundo. A semente conta de lágrima, mboy em língua guarani, pertence a Ñandesy, e segundo Daniel, há pelo menos três grandes motivos para que ela seja usada num dos artefatos que porta o rezador, o jeasaha (colares de conta de lágrimas cruza-dos no peito), de acordo com conhecimentos dos antigos:

ela existe lá no quintal de Ñandesy. Ela tem a possibilidade de cura pois esfria as coisas. Se você vai curar uma doença, benzer uma pessoa doente, se você vai curar, então sua mão tem que estar bem fria, porque todo ñembo'e do kaiowá vai nessa direção de apagar o fo-go do corpo. A segunda é porque, quando você está rezando, é tipo um uniforme. A lágri-ma é que vai te manter leve para você acompanhar as viagens cosmológico-geográficas. Além disso, os colares de mboy são usados cruzados nesse uniforme porque é uma imita-ção dos Overava, imitação de Ñanderu. Minha avó, bisavó, explicava: quando você mor-rer, aquele guia que vai te levar, então o teu espírito transforma naquele jeasaha que é um $X$ para que nenhum poder maligno, ela falava, um añã não visse você. Porque você vai passar por um lugar que se você, durante a sua vida terrena, teimou, matou, bateu em al-guém, você não se transformará naquele jeasaha em forma $X$ no corpo daquele guia que vai passar por aquele espaço. Então logo o añã vê você e você seria pego e castigado. A minha bisavó falava para nós, você não vai teimar sua mãe porque senão você não vai passar por isso. Então nós Kaiowá crescemos acreditando nisso e em profundo respeito por nossa mãe (VASQUES, 2016b).

São, portanto, três os fatores de conexão agenciados pela semente e sua força (mbareté) como meio: as qualidades do resfriamento, a leveza e a geração de reconhecimento nas relações com os parentes sagrados e terrenos (especialmente a mãe) no processo da reza ritual. Tais fatores são res-ponsáveis pela condução à perfeição (aguyje): os encontros com os parentes ancestrais e com Ñande-ru, o pai celestial, o respeito à mãe suprema, Ñandesy, corporificada nas mulheres do convívio coti-diano, o aprendizado dos caminhos e a capacidade de ouvir as mensagens e trazê-las aos parentes terrenos. Os rezadores circulam num espaço a um só tempo geográfico e local, cosmológico e astral quando rezam, espaço permeado por ondas de brilho (rendy), raios (vera) e seus donos (overava). Mas só os mais eficientes e melhor formados têm o poder de alçar os mais altos e diversos patamares celestiais (para os Kaiowá, há 15 patamares no céu acima de nós, chamados de teta). Em cada um deles, 
o rezador encontra ñanderamõi (parentes ancestrais, nossos avós) e os jara (os deuses parentes da segunda geração) que mandam mensagens aos parentes da terra e também acontece de, por vezes, estes se fazerem ver e ouvir sem que os parentes da terra os percebam no momento da conversação como seres sagrados ou pertencentes ao plano celestial. Essa comunicação entre parentes - os nhanderamõi/jara e os viventes na terra - é permanente. A cada semana, nas quintas-feiras, dia em que a passagem ao plano cosmológico está aberta, Valdomiro Flores vai ouvir o que eles têm para falar pela reza ritual e, por vezes, ele também recebe mensagens dos parentes invisíveis em sonhos.

Em geral, um rezador domina as tecnologias de conexão com os parentes invisíveis, a reza e os artefatos sagrados que a potenciam, bem como os poderes de agenciamento da comunidade e da família para a transmissão de conhecimentos fundamentais à sua manutenção. Não necessariamente todas essas qualidades pertencem a um mesmo rezador. Há aqueles que se dedicam de maneira es-pecial à fabricação dos artefatos sagrados. O jeasaha é um desses artefatos. Feito com as sementes mboy especialmente escolhidas e colhidas para esse fim, em todo o processo de feitura, o rezador potencia seus poderes com cantos e evocações. A semente também faz parte da construção mbaraka, instrumento musical que é responsável pela conexão do rezador com o mundo espiritual. É o chama-riz dos espíritos e, por isso, conhecido como "celular para falar com Ñanderu"4. Para os kaiowá, os deuses são famílias, não são uma única pessoa como nas religiões monoteístas, o rezador é um elo de interconexão entre as famílias terrenas e extraterrenas, fazendo com que a comunicação entre elas seja próxima e rápida, que habitem um mesmo tempo-território - o tekoha - marcado pelas histórias dos antepassados e por forças geográficas como árvores, rios, montanhas, florestas específicas.

A luta política pela terra é, em grande medida, guiada por essas conversações entre os huma-nos e os deuses, incluindo todos os seus sinais e os agentes dos quais eles são guardiães, como as tempestades, o vento, o relâmpago, o sol, as plantas, os animais. A semente mboy está ligada, no plano cosmológico, à precipitação da força protetora da

\footnotetext{
4 Essa expressão ganhou notoriedade entre os brancos a partir do filme Terra Vermelha (2008), de Marco Bechis, mas já era de uso corrente entre os Kaiowá como forma de explicar a conexão comunicacional entre Rezador, o grupo que reza e o mundo espiritual.
} 
grande mãe, mas também por acompanhar os processos de circulação internos ao mundo cósmico tanto como forma de dar força e leveza quanto de gerar identificação com os as famílias de deuses, tornando o kaiowá reconhecivel por esses parentes. De modo prático e por tais ligações cosmológicas, a semente auxilia em processos de cura e também no estabelecimento da comunicação com os pais celestiais ancestrais agenciados pela força do mbaraka. Por isso, podemos dizer que esse pequeno elemento - indissociavelmente, natureza e cultura - guia as conversações que orientam sobre as estratégias, táticas e alertam a respeito de di-versos perigos (BENITES, 2014). Caminhar até os deuses na reza ritual é "embelezar e fortalecer os corpos, dotando-os de força e de alegria, combatendo a tristeza, pois é de sua responsabilidade essa espécie de treinamento e preparação para a vida, o que garante a sobrevivência do grupo e a manu-tenção da própria Terra, numa ação análoga à desenvolvida pelos deuses" (MONTARDO, 2009, p. 15).

Essa interconexão permanente é fundamental para a resistência: ela fortalece os grupos e in-dica os caminhos a serem perseguidos. Esse fortalecimento alcança também as pessoas, nutrindo-as de capacidade para viver a vida com alegria, ideia que nos sugere aproximar daquilo que chamamos de subjetivação política. Os nhanderamõi mandam mensagens particulares e observam/cuidam de seus parentes terrenos nos tortuosos caminhos da existência: afastam a tristeza (ñe'emyrõ) que pode conduzir à caça de si com morte por suicídio e dão forças para participação nos rituais de sociabili-dade, das rezas para cuidar do ñe'e (alma-palavra) e dos rituais ligados à agricultura e à preservação, à medicina e à alimentação.

O Raio sagrado que vejo deixa-me pleno de felicidade pois me precipito na travessia do grande caminho. (Excerto reza longa) 


\title{
Reunidos em rosário: lágrima, irmandade e matriz africana do Reinado ${ }^{5}$
}

\author{
Ai eu não sou daqui \\ Eu sou do lado de lá \\ Eu vim da Kalunga ${ }^{6}$ \\ Ouvindo sereia cantar \\ (Toada de Massambique)
}

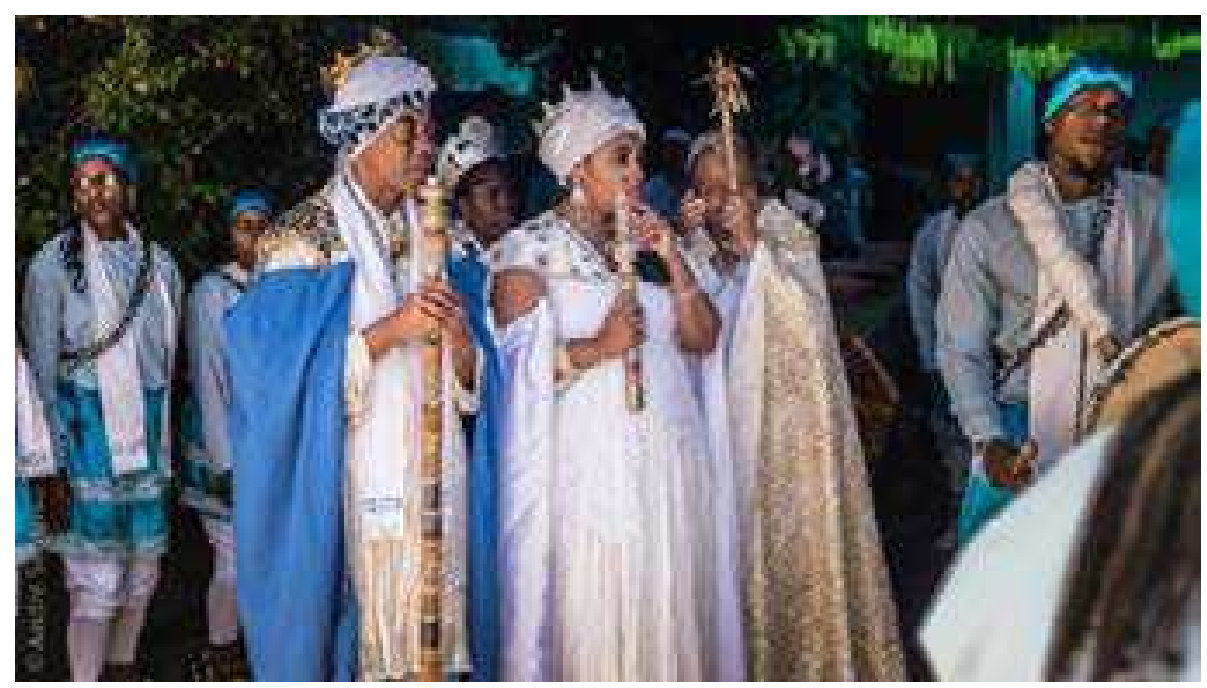

Imagem 2 Saudação ao Trono Coroado, 2016. Foto: André Santos (cedida à Bárbara Altivo

Segundo Pedrina de Lourdes dos Santos (2016), Reinado é o jeito de rezar que vem do lado de lá, das terras de além-mar, África ancestral. Capitã de massambique de N. Sra. das Mercês na cidade de Oliveira (MG),

\footnotetext{
5 Relato de Bárbara R. Altivo. Elaboro na comunidade do Reinado de Oliveira-MG a pesquisa que resultou na tese de doutorado "Rosário dos Kamburekos: Espirais de cura da ferida colonial pelas crianças negras no reinadinho (Oliveira-MG), focada na produção comunicacional de ancestralidade pela relação entre os mais novos - kamburekos (espíritos infantis) e crianças que fazem o Congadinho, uma vivência reinadeira constituída de forma autônoma por elas - e os mais velhos, capitães, reis e rainhas negros, pretos-velhos e Mkisi (entidades espirituais). A pesquisa de cam-po compreendeu o período de 2016 a 2018 e o trabalho com a comunidade continua sob diversas formas de colabo-ração. A tese foi orientada por Luciana de Oliveira e co-orientada por Pedrina de Lourdes dos Santos, intelectual reina-deira e professora do Programa de Formação Transversal em Saberes Tradicionais da UFMG.

6 Mar e, ao mesmo tempo, a terra dos mortos, os ancestrais, na língua quimbundo de matriz bantu, tronco linguístico oriundo da região centro-sul africana.
} 
Pedrina de Lourdes Santos é uma ilustre sacerdotisa e teórica do universo do Reinado, além de muzenza (filha de santo no candomblé), intelectual da cultura e língua de ori-gem bantu, rezadeira e benzedeira, liderança espiritual e política da irmandade dos Leonídios. Aos 11 anos de idade, com a permissão do pai, antigo capitão da guarda de massambique ${ }^{7}$ das Mercês, Pedrina entra como dançadora no Reinado, posto que até então era ocupado apenas por meninos. Herda a capitania, juntamente com o irmão Antônio dos Santos, em 1980, com a morte do pai. Ela é considerada uma das primeiras mulheres capitã de massambique de Minas Gerais, e assim enfrentou dificuldades para ter acesso aos conhecimentos tradicionais e firmar a sua liderança na comunidade reinadeira (SOARES, 2016). Com 47 anos de festa do rosário e 37 de capitania, Pedrina é uma ver-dadeira guardiã dos fundamentos africanos no Reinado de Oliveira, lutando contra as constantes investidas embranquecedoras, catolicizadoras e espetacularizantes da igreja, mídia e elite da cidade.

"Esse povo era de muita sabedoria, o povo reinadeiro, desde o tempo da escravidão. Eles conseguiram preservar sua crença, sua fé, sem precisar mais morrer no tronco." A cada novo sol que desponta, Pedrina se declara mais impressionada com a esperteza dos negros escravizados diante da violência colonial do catolicismo. O povo do rosário, como ela costuma dizer, elaborou uma festa assentada na matriz cosmológica africana, em toda a sua complexa efetivação ritual pelo canto, to-que e dança, por meio da devoção aos santos católicos. A nomeação da festa como Reinado passa por uma antiga disputa de poder na linguagem, contenda na qual Pedrina faz questão de tomar parte. A capitã não gosta do termo Congado ou Congadas, muitas vezes usado como sinônimo de Reinado pela boca dos folcloristas e acadêmicos. "Congado é enfeite, espetáculo. Reinado tem fundamento, mandamento e sacramento. Sabe de onde vem e para onde vai." Artista e artesã da cura pela reza, Pedrina sabe muito bem que a palavra carrega magia, agência, e prefere aquelas que ativam o berço africano do Reinado, a sua força espiritual calcada na ancestralidade, nas memórias dolorosas do tempo do cativeiro e na comunicação com as almas, santos e divindades do outro mundo. No dizer da Rainha Perpétua de N. Sra das Mercês do Jatobá e professora na

7 Massambique é como Pedrina denomina o tipo de guarda que capitaneia, comumente chamada de Moçam-bique, responsável por guarnecer os reis e rainhas coroados no Reinado. Segundo ela, o termo Massambique é o mais adequado porque deriva da matriz linguística quimbundo, significando "dança sagrada que vem de Angola". 
UFMG, Leda Maria Martins:

Ternos ou Guardas de Congo podem existir individualmente, ligados a santos de devoção em comunidades onde não exista o Reinado. Os Reinados, por sua vez, são definidos por uma estrutura simbólica complexa e por ritos que incluem não só a presença das guardas, senão a instauração de um império, cuja concepção inclui variados elementos, atos litúrgicos e cerimônias e narrativas que, na performance mitopoética, reinterpretam as travessias dos negros de África às Américas. (MAR-TINS, 2013, p. 28).

Durante nove dias, na primeira semana de setembro, as guardas de vilão, massambique, cato-pé e congo ${ }^{8}$ percorrem as ruas de Oliveira com seus tambores, fardas coloridas, bandeiras, bastões, espadas e uma série de outros de objetos sagrados, fazendo o deslocamento festivo das majestades. Os reis e rainhas congos e perpétuos, muito respeitados pelas comunidades reinadeiras, são a presen-ça negra dos santos cultuados: N. Sra. do Rosário, N. Sra. das Mercês, São Benedito, Santa Efigênia e N. Sra. Aparecida. Além deles, há os reis e rainhas de promessa e de ano, que mudam a cada festa e são por vezes brancos, vestidos ao modo europeu. Cada guarda ou terno é regido por um santo, que vai na frente em forma de bandeira, anunciando a chegada do grupo, varrendo a passagem dos maus agouros, guiando na cabeceira do fluxo o caminho por onde dançam, tocam e cantam os mem-bros da guarda, de acordo com a condução da capitã ou do capitão. Uma estrutura ritual que faz a travessia das coroas contando a história da travessia dos negros, desde as terras africanas até o Brasil, o terror das viagens nos navios negreiros, as violências sofridas, e o brado de libertação: "levanta minha gente, cativeiro acabou!".

A ritualística cantada e dançada pelas guardas reinstaura a aparição de Nossa Senhora do Rosário, mito fundador do Reinado. Pelas águas do mar chegou a senhora que aliviou a dor e o so-frimento dos negros, a grande mãe que não se deixou ser capturada pelo catolicismo branco e seguiu sentada sobre o tambor de candombe ${ }^{9}$ até a casa sagrada dos negros, os seus terreiros. A Senhora do Rosário chorou, chorou muito com

8 Tipos de guardas, agrupamentos de dançadores e tocadores, que cultuam os santos de acordo com as especificidades de seu estilo ritual.

9 Ritual de devoção aos ancestrais africanos que consiste no canto, dança e toque de três tambores: Santana, Santaninha e Jeremias. Abre a festa do Reinado de Oliveira, acontecendo na madrugada de sábado para domingo. 
e pelos negros. A crueldade humana, o peso da chibata, as humi-lhações, as torturas, todas a dores da escravidão fizeram a santa derramar um desatino de lágrimas, que no chão viraram sementes. Grãos formadores do Rosário dos Pretos, contas fecundantes ligadas pelo fio da irmandade, marca de um povo que laboriosamente transcria as memórias e os laços de parentesco desterritorializados com violência pela diáspora escravagista. O rosário é artefato que cruza o peito dos reinadeiros, é instrumento de proteção, cura e benzeção, é conta de umbanda e candomblé, é a festa, é a própria comunidade. A polivalência desse rosário deslinda a filosofia negra e usos rituais afro-brasileiros de um elemento marcadamente católico, astúcia de quem soube se infil-trar no seio dos símbolos cristãos e mobilizá-los africanamente, herança mítica que "se imbricou no tecido da hagiografia católica, modificando-a e modificando-se” (LOPES, p. 102, 1988).

As contas de lágrimas reunidas em Rosário estão presentes de diferentes maneiras e intensi-dades tanto nos rituais festeiros da irmandade dos Leonídios (no reinado, umbanda e candomblé) quanto no cotidiano. Rosário cruzado fecha o corpo. São tecnologias de defesa contra feitiço, olho grande e todos os tipos de ameaças que correm soltas nos dias de festa, as quais também se manifes-tam em forma de preconceito racial e ódio religioso. Os congadeiros não fazem nada sem a sua "ar-madura" ao longo dos nove dias de cortejo pela cidade. A festa é muito forte, e por isso mesmo ex-tremamente perigosa. "O Reinado move céus, terra e mar!", costuma dizer Pedrina. Os cantos e to-ques têm o poder de curar ódio, tristeza, rancor, memória de tempos dolorosos. Enfermidades das gentes do mundo dos vivos e daquelas que habitam o lado dos mortos, sobretudo das almas dos antigos negros escravizados, torturados, e de seus senhores e algozes. "Há um peso cármico que vem da escravidão que é muito forte na cidade de Oliveira, e no Brasil como um todo". O rosário de Ma-ria é um enorme e complexo labor de cuidado com o povo de cá e de lá que vive imantado pelas agruras daquela época. Tempo que se vê reinstaurado na vida pública da cidade no período do feste-jo a partir de uma estrutura ritual fundada no deslocamento do trono coroado, guarnecido pelos dançadores e tocadores dos ternos, ao longo das ruas - pelas suas casas, encruzilhadas, cemitérios, comércio, escolas e demais espaços povoados por múltiplos seres, memórias e rastros da experiência da escravidão. 
Os pretos-velhos, espíritos de antigos negros cativos, nos toques de umbanda que transcor-rem a madrugada na sede dos Leonídios, costumam chacoalhar os rosários ao redor dos corpos do-entes, "descarregando" todos os maus agouros instalados. Os aparelhos, cavalos ou médiuns usam os colares da semente como espécie de conta ou guia, com a função de proteção, conexão com os espíritos e demarcação do pertencimento ao Reinado no plano dos espíritos. Marca dos reinadeiros e conexão entre eles, o rosário é lido como peça macabra pelas famílias brancas de Oliveira, elas mes-mas ligadas ao contexto escravagista pelo lado da casa grande, continuidade dos senhores donos das lavouras de café que até hoje são sustentadas pelo trabalho dos negros da região. Nesse contexto, o objeto recebe o seguinte estigma: coisa de "preto macumbeiro". Um abismo social e racial grita na topografia da cidade, em seu comércio, divisão de trabalho e renda. Portar o rosário no peito é car-regar um lugar, uma história, um compromisso comunitário diante da hostilidade do olhar que vigora na cena pública de Oliveira. É ter a coragem de dizer de si, reconhecer-se perante aos seus e aos ou-tros, armar-se e seguir na labuta da vida: "isso é o que nos dá força para levantar o dia-adia”, expli-cou-se Hudson, capitão do Congadinho de N. Sra. Do Rosário, em uma das nossas conversas na sede onde as crianças vivem o reinado à sua maneira.

As contas do meu rosário São balas de artilharia, Dá combate no inferno Enquanto rezo Ave-Maria (Toada de massambique)

\section{Subjetivação política, natural, social}

O que essa encruzilhada de campos, complexa e espessa em cada uma de suas entradas, pode nos ensinar - ampliando aqui o lugar de aprendizagem para o diálogo intercultural e interepistêmico - sobre processos de subjetivação política? Como chama a atenção Catherine Walsh a partir da abordagem da interculturalidade, em oposição às opções autoritárias do multiculturalismo, da diver-sidade na unidade ou da mestiçagem, esta se vê como contra-hegemônica "enfocada en 
revertir la designación (...) de algunos conocimientos como legítimos y universales y la relegación de otros, especialmente aquellos relacionados con la naturaleza, el territorio y la ancestralidad, al espacio local de saberes, folklore o del mundo de la vida". (2002, p.22)

É nessa linha de pensamento que localizamos, a partir dos diversos dados etnográficos apre-sentados, o fortalecimento da subjetividade agenciado pela conta de lágrima tanto num movimento centrípeto, ou seja, como meio de comunicação de coletivos e comunidades, quanto centrífugo, ou seja, no diálogo intercultural. Os processos de subjetivação política em tela não depuram natural e social na relação com a ancestralidade, nos processos de reconhecimento mútuo entre parentela divi-na e terrena, na força feminina que os enseja, nas tecnologias e manejos precipitados pelos líderes religiosos, intelectuais, filósofos e cientistas do xamanismo Kaiowá ou do Reinado de matriz africa-na, bem como no treinamento de qualidades essenciais para o preparo e enfrentamento das lutas.

A relação com ancestralidade, localizada no tempo mítico e histórico, vivenciada cotidiana-mente, permite ao sujeito enxergar-se como pertencente a uma linhagem. A conta é experiência viva que colada aos corpos indígenas e negros, sob a forma de colares, ou seja, de contas encaixadas em sequência, reafirma esse pertencimento, o não estar sozinho no mundo. Saber de onde se vem, saber que de onde se vem é um lugar bonito, fortalece as conexões presentes e as relações com os ances-trais naturais, as forças da natureza (ar, água, terra, fogo) que são também qualidades no ser e marcas no grupo. Isso promove um senso de preservação ampliado e a dilatação das possibilidades recursivas de expressão de si e tecnologias do comum em face de processos genocidas, epistemicidas e cosmicidas que apagam ou demonizam os ancestrais, destruindo mundos e impondo a biopolítica (PELBART, 2007).

As linhagens ancestrais retrocedem e conduzem à força mítica da mãe protetora maior, a força da mulher que, como portal sagrado de mundos, a dona da vagina, traz os seres à vida no plano físi-co e os reconduz a outras vidas. Essa força se consubstancia nos casos e campos nas criaturas sagra-das de Ñandesy e Nossa Senhora do Rosário, dotadas de um afeto infinito que ampara e sustenta, base do respeito às mães terrenas, esposas, irmãs, companheiras e conselheiras com quem se compar-tilha nos cortejos sagrados e na luta pela terra originária. Essa força da mulher é claramente um con-traponto ao outro hostil e às lógicas 
masculinizantes do capitalismo e seus arcabouços morais finca-dos no patriarcalismo. A conta é planta do quintal de Ñandesy, é a lágrima justiceira de Nossa Se-nhora do Rosário. Não por acaso, ela é a vestimenta que gera reconhecimento no mundo espiritual ou no plano cosmológico com os parentes não terrenos e, também, nas arenas públicas, a afirmação política de um modo de vida, signo vivo da coragem de criá-lo, vivê-lo e defendê-lo.

Por fim, é preciso lembrar que a conta é tecnologia de acesso ao mundo espiritual do qual se valem rezador e reinadeira, manejadores das forças da natureza e da conexão com os parentes de hoje, de ontem e de sempre com quem desenvolvem relações próximas e íntimas. Ser portador des-sas habilidades - recebidas dos governos maiores e/ou aprendidas ao longo da vida inteira - exige disciplina que desafia a subjetividade e nada tem a ver com a régua geradora de equivalências do capital ou com o que poderíamos chamar de subjetivação capitalística que busca promover o gozo no consumo (GUATTARI, 2000). Nesse mesmo sentido, a leveza propiciada pela conta para a viagem no plano cosmológico do povo Kaiowá, ou no descarrego do Rosário dos reinadeiros, desafia também essa conexão viciada com o consumo, afirmando o que chamamos de contempla-ção/arrebatamento, como fundamento dos deslocamentos entre mundos. Cada um dos agentes pro-piciadores, o rezador que veste o jeasaha e manipula o mbaraka, a reinadeira que manipula e veste o Rosário comandando os tambores e instrumentos rituais, são a um só tempo mestres e trabalhadores da palavra, da cura - de modo indissociável a cura de si, a cura coletiva, a cura da memória -, são bibliotecas vivas, intelectuais que precisam estudar, reconstituir o saber e disseminá-lo, além de di-plomatas nas políticas intermundos. Para tudo isso, é preciso contar com a força da conta, além de respeitar rígidos códigos de conduta no que tange à alimentação, aos cuidados do corpo e do espíri-to e à observância de diversos tipos de interdições. Nossa encruzilhada de mundos leva-nos a reco-nhecer no modo como reinscrevem as relações entre natural e social como agenciamentos contraco-loniais com potência de nos fazer revisar nossas formas de colonialidade. 


\section{Meio é gente: breves considerações finais}

As formas de vida observadas, descritas e experimentadas tanto nas relações de campo quan-to nas relações textuais, existem sob muitos riscos. Não gostaríamos de agregar a eles o risco de "matá-las" ao dizer que só fazem sentido quando se encaixam ou exemplificam conceitos e categori-as de pensamento canonizados. Ao contrário, no ritmo do movimento indutivo que vimos percor-rendo, gostaríamos que nosso pensamento se deixe tocar de forma sensorial e afetiva por essas for-mas de vida e seus regimes de conhecimento. Portanto, não nos interessa realizar aqui um procedi-mento classificatório ou de validação da semente como meio ao relacioná-la com o pensamento de autores ocidentais, europeus e distantes dos lastros empíricos aqui apresentados.

O jeasaha e o Rosário são usados publicamente, não são objetos sobre os quais prevaleça nenhum tipo de tabu e têm os poderes da proteção. Mesmo visíveis e atuantes como força protetiva, impulsora e geradora de vínculos em múltiplos planos, seus poderes são desqualificados como parte da colonização do pensamento e do racismo que a sustenta, relegando tal saber ao lugar de "coisa de índio atrasado" ou "coisa de preto macumbeiro". A diferença epistêmica contra um saber que é da ordem do corpo, da reza e da fé em muitos sentidos coloca teorias e conceitos da comunicação em risco. No limite, são experiências que subvertem a ideia de meio como tecnologia inanimada e de mediação como ação de um substrato cultural prévio à ação. Como meio - tecnologia de conexão - ou mediação - invenção de linguagem que repõe e repara o vínculo -, a conta de lágrima/mboy tem ela própria agência dentro dos processos comunicacionais multidimensionais.

Tais processos comunicacionais - pensados como fórum cosmopolítico (OLIVEIRA; FLO-RES; GOMES; VASQUEZ; 2016; OLIVEIRA, 2016; OLIVEIRA, 2018), posto que recolocam múltiplas agências, inclusive àquilo que é percebido apenas como objeto da ação de um sujeito cognoscente universal - situam-se no terreno do que Walsh (2002) chamou de interculturalização de via múltipla, cujo acontecer segue fluxos de baixo para cima, da ação local às transformações sociais. Neles as formas dos mundos, ao se encontrarem, transformam-se mutuamente. Aqui o que sugerimos é pensar que os meios são também agências produtoras de fluxos e processos. Como a lágrima/mboy, os meios podem ser reperspectivados, ganhando uma humanidade própria. 


\section{Referências}

AGAMBEN, G. Form-of-life. In: AGAMBEN, G. Means Without End: Notes on Politics. Trad. Vincenzo Binetti e Cesare Casarino. Minneapolis: Univ. of Minnesota Press, 2000

ALMEIDA, R. T. Do Desenvolvimento Comunitário à Mobilização Política - O Projeto Kaiowa-Ñandeva como experiência antropológica. Rio de Janeiro, Contra Capa, 2001.

BENITES, Tonico. Rojerokyhina ha roikejevytekohape (Rezando e lutando): o movimento histórico dos AtyGuasu dos Ava Kaiowa e dos Ava Guarani pela recuperação de seus tekoha. 2014. Tese (Doutorado em Antropologia Social) - Museu Nacional/Universidade Federal do Rio de Janeiro, Programa de Pós-graduação em Antropologia Social, Rio de Janeiro, 2014.

BRAND, A. J. O confinamento e seu impacto sobre os Paì-Kaiowá. Porto Alegre. Dissertação (mes-trado). PUC/RS,1993, 210p.

- O impacto da perda da terra sobre a tradição kaiowá/guarani: os difíceis caminhos da pa-lavra. Porto Alegre. Tese (doutorado em História). PUC/RS, 1997, 345p.

FLORES, V. Artes Ofícios dos Saberes Tradicionais. [Aula]. Módulo Cosmociência Kaiowa. Belo Horizonte, UFMG, 2014 (Tradução de Genito Gomes).

Formação Transversal em Saberes Tradicionais [Aula]. Disciplina Ojuhu Ñe'e/Mbopaje Ñeé. Encontrar a palavra/Encantar a palavra. Belo Horizonte, UFMG, 2016 (Tradução de Genito Gomes e Daniel Lemes Vasques).

GUATTARI, F. Cartografías esquizoanalíticas. Buenos Aires, Manantial, 2000.

LOPES, N. Bantos, males e identidade negra. Rio de Janeiro, Forense Universitária, 1988

MARTINS, L. M.; Afrografias da memória. Perspectiva: São Paulo, 1994.

MONTARDO, D. L. Através do mbaraka: música e xamanismo guarani. Tese [Doutorado em An-tropologia Social], Universidade de São Paulo, 2002.

OLIVEIRA, L.; BENITES, T. ; OLIVEIRA NETO, R. . Sacrifício e quase-ᄀ-acontecimento: aponta-mentos sobre a visibilidade da luta pela terra dos povos indígenas Guarani e Kaiowa. Cadernos de História, v. 17, p. 114-142, 2016.

OLIVEIRA, L.; FLORES, V. ; GOMES, G. ; VASQUES, D. L. . Ñande Reko Marangatu: a reto-mada, a imagem e a constituição de fóruns cosmopolíticos. 2016. (Apresentação de Traba-lho/Conferência ou palestra).

OLIVEIRA, L.. Bro MCs Rap Indígena: o pop e a constituição de fóruns cosmopolíticos na luta pela terra Guarani e Kaiowa. Revista EcoᄀPós, v. 19, p. 199ᄀ220, 2016.

OLIVEIRA, L. Etnografia, pesquisa multissituada e produção de conhecimento no campo da co-municação. Questões Transversais: Revista de epistemologias da comunicação, v. 5, p. 72--81, 2017.

OLIVEIRA, L. Na aldeia, na mídia, na rua: reflexões sobre a resistência Kaiowa e Guarani em diá-logo com o contexto de golpe político no Brasil e com o campo hegemônico da comunicação. Revis-ta Mídia e Cotidiano, PPGMC/UFF, 2018

OLIVEIRA, L. e BOMBA, P. Colonialidade da memória: apagamentos da luta pela terra Guarani e 
Kaiowá na constituição do moderno agronegócio brasileiro. Revista Dispositiva. Programa de Pós-Graduação da PUC-Minas, v. 7, n. 12, 2018.

PELBART, P. P. Biopolítica. Sala Preta (Revista PPGAC/USP), v. 7, pp. 57-65, 2007.

SANTOS, A. B. dos. Colonização, Quilombos: modos e significados. Brasília: Instituto de Inclusão do Ensino Superior e na Pesquisa (INCTI/UnB), 2015.

SANTOS, P. de L. dos. Formação Transversal em Saberes Tradicionais [Aula]. Disciplina Catar Fo-lhas: saberes e fazeres do povo de axé. Belo Horizonte, UFMG, 2016.

SOARES, D. 2016. "Muita religião seu moço!" Os caminhos de uma congadeira". Tese (Doutorado em Antropologia) - Programa de Pós Graduação em Antropologia da UFSC; Florianópolis, 2016.

PEREIRA, Levi. A atuação do órgão indigenista oficial brasileiro e a produção do cenário multiét-nico da Reserva Indígena de Dourados, MS. Trabalho apresentado no 380 Encontro da ANPOCS, Caxambu, 2014.

VASQUES, D. L. Formação Transversal em Saberes Tradicionais [Aula]. Disciplina Ojuhu Ñe'e/Mbopaje Ñeé. Encontrar a palavra/Encantar a palavra. Belo Horizonte, UFMG, $2016 \mathrm{a}$.

. Entrevista concedida a AUTORX1. Belo Horizonte, novembro/2016.

O mito de origem da formação da terra segundo o Kaiowa. Monografia [Conclusão de Graduação em História]. UEMS, Departamento de História, 2012.

WALSH, C. (De)Construir la interculturalidad. Consideraciones críticas desde la política, la colonia-lidad y los movimientos indígenas y negros en el Ecuador. In: FULLER, N. (ed.) Interculturalidad y Política, Lima: Red de Apoyo de las Ciencias Sociales, 2002. 


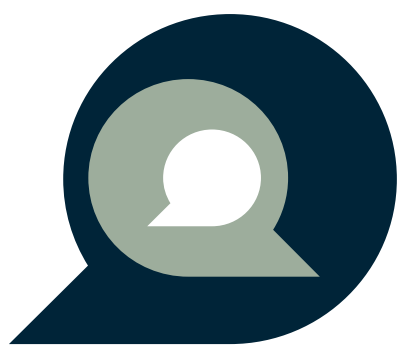

